Department of Epidemiology and Social Medicine, University of Aarhus, Vennelyst Boulevard 6, DK- 8000 Aarhus C, Denmark

L Kaerlev

S Sabroe

Department of Occupational Medicine, Aarhus University Hospital Aarhus, Denmark

L Kaerlev

H A Kolstad

Institute of Pathology, Aalborg Hospital, Aalborg, Denmark P S Teglbjaerg

Bremen Institute of Prevention, Research and Social Medicine (BIPS), Bremen, Germany W Ahrens

Department of Oncology, University Hospital Lund, Lund, Sweden

$M$ Eriksson

Unit of Public Health, Hygiene and

Environmental Health, Faculty of Pharmacy,

Valencia University,

Valencia, Spain

A L González

Institut National de la Santé et de la

Recherche Médicale,

Unité 88, Hôpital

National de

Saint-Maurice, France

P Guénel

Department of Oncology, Orebro

Medical Center,

Örebro, Sweden

L Hardell

Registre des Tumeurs

Digestives du

Calvados, France

G Launoy

Center for Study and Cancer Prevention,

Unit of Epidemiology,

Florence, Italy

E Merler

Department of Biomedical Sciences and Human Oncology, University of Turin, Turin, Italy

F Merletti

Unit of Public Health, Hygiene and

Environmental Health, Faculty of Pharmacy, Valencia University, Valencia, Spain M M M Suárez-Varela

Institute for Medical Informatics, Biometry and Epidemiology, Medical Faculty, University of Essen, Essen, Germany A Stang

Correspondence to: Dr Linda Kaerlev

L.kaerlev@dadlnet.dk

Accepted 23 June 2000

\title{
Occupation and small bowel adenocarcinoma: a European case-control study
}

Linda Kaerlev, Peter Stubbe Teglbjaerg, Svend Sabroe, Henrik A Kolstad, Wolfgang Ahrens, Mikael Eriksson, Agustin Llopis González, Pascal Guénel, Lennart Hardell, Guy Launoy, Enzo Merler, Franco Merletti, María M Morales Suárez-Varela, Andreas Stang

\begin{abstract}
Objectives-Because of the rarity of small bowel adenocarcinoma (SBA), little is known about the aetiology of this disease. This study aimed to identify occupational clustering of cases SBA as a systematic approach to new hypotheses on the aetiology of this disease.
\end{abstract}

Methods-A European multicentre casecontrol study was conducted in 1995-7, inclusive. Incident cases aged 35-69 years with SBA $(n=168)$ were recruited before acceptance by a pathologist. Altogether 107 cases and 3915 controls were accepted, of which 79 cases, 579 colon cancer controls, and 2070 population controls were interviewed.

Results-The strongest industrial risk factors for SBA taking account of 10 years' exposure lag were dry cleaning, manufacture of workwear, mixed farming (women), and manufacture of motor vehicles (men). A significantly increased risk of SBA (odds ratio (OR) and $95 \%$ confidence interval $(95 \% \mathrm{CI})$ ) was found among men employed as building caretakers, OR 6.7 (1.7 to 26.0) and women employed as housekeepers, OR 2.2 (1.1 to 4.9); general farm labourers, OR 4.7 (1.8 to 12.2); dockers, OR 2.9 (1.0 to 8.2); dry cleaners or launderers, OR 4.1 (1.2 to 13.6); and textile workers (sewers or embroiders), OR 2.6 (1.0 to 6.8). For the last four groups, together with welders OR 2.7 (1.1 to 6.6) (men) an exposure-response pattern was found when calculating the ORs for jobs held 1-5 years and $>5$ years, with never having held the job as reference. The ORs (95\% CIs) for $1-5$ years and $>5$ years were $4.3(0.4$ to 44.0$)$ and $3.5(0.9$ to $13.7), 3.0(0.3$ to 26.2$)$ and $4.3(0.9$ to 21.2$)$, $4.6(0.4$ to 48.1$)$ and $11.0(2.0$ to 60.4$), 1.3$ (0.2 to 11.0$)$ and $5.8(2.0$ to 17.2$)$, and 2.8 (0.3 to 23.8$)$ and $4.6(1.3$ to 16.6$)$, respectively, for each of these occupations. Among welders, people performing semiautomatic arc welding (MIG/MAG) were identified as a high risk group (OR 5.0 (1.3 to 19.6)).

Conclusions-This explorative study suggests an increased occurrence of SBA in certain occupations, which needs further evaluation.

(Occup Environ Med 2000;57:760-766)

Keywords: small intestine; adenocarcinoma; occupational risk factors
Primary small bowel adenocarcinoma (SBA) is a rare cancer of unknown aetiology. The annual incidence in Europe is less than 1/100 000. ${ }^{1}$ Crohn's disease, ${ }^{2}$ familial adenomatous polyposis, ${ }^{3}$ dietary factors, tobacco smoking, alcohol consumption, ${ }^{4}$ and social status ${ }^{5}$ have all been suggested as risk factors for SBA, but the evidence is sparse and the results inconsistent. A worldwide relatively high male:female ratio in Europe of about 1.5-2.0:1 may point towards a potential occupational aetiology. ${ }^{1}$ Occupations such as stoker, cashier, waiter, and worker at spinning mills, ${ }^{6}$ white collar worker, ${ }^{7}$ forestry worker, ${ }^{8}$ as well as exposure to cooking fumes, ${ }^{9}$ pesticides, ${ }^{10}$ asbestos, halogenated aromatic compounds, solvents, and cutting oils ${ }^{11}{ }^{12}$ have been associated with SBA, but only based on single studies or case reports.

The rarity of SBA indicates that it is caused by infrequent exposures. Lifestyle factors are not expected to play a major part, unless they operate in combination with rare factors. Most occupational carcinogenic exposures, on the other hand, are rare and potential causal candidates. The history of cancer epidemiology has described several examples of rare cancers caused by rare occupational exposures, the so called "signal cancers". Well known examples are mesothelioma in asbestos workers, hepatic haemangiosarcoma in vinyl chloride workers, and osteosarcoma in watch dial painters exposed to radium. ${ }^{13-15}$ The causes of these rare cancers were all identified because they clustered in well recognised occupational groups with a common rare exposure. The present study was designed to be a systematic search for industrial and occupational clustering of small bowel adenocarcinoma based on lifetime job history as an approach to generate new hypotheses on the aetiology of this disease. High odds ratios (ORs) were to be expected if occupations or industries with a causal exposure were detected due to the low background disease rate.

\section{Material and methods}

An international multicentre case-control study was conducted in 10 European countries in 1995-7. The project used the same data collection instruments to investigate occupational, medical, and lifestyle risk factors for seven rare cancers (small bowel, thymus, bone, gall bladder, male breast, skin (mycosis fungoides), and eye (malignant melanoma)). Cases of SBA and frequency matched controls were identified in six of these countries. The control groups for 
all cancer types in these countries were pooled for analyses.

The following national regions participated: Denmark (the whole country), Sweden (Umeå, Örebro/Uppsala, Linköping, and Lund), France (Calvados, Côte d'Or, Doubs, Hérault, Isère, Bas-Rhin, Somme, Manche, Haut-Rhin, and Tarn), Germany (Hamburg/Bremen, and Essen/Saarland), Italy (Turin, Florence, and Eastern Veneto), and Spain (Valencia, Navarra, and Pais Vasco). The populations of each of these areas are about 5 million, 4 million, 6 million, 4 million, 3 million, and 6.5 million, respectively. Incident cases aged 35-69 years were recruited in the well defined geographical regions. Case identification was based on repeated requests to hospital and pathology departments, and by frequent screening of regional or national cancer and pathology registers.

Histologically and clinically verified cases of SBA with topography codes 152.0-152.9 (ICD-O, 1976) or C17.0-C17.9 (ICD-O, 1990) and morphology codes 80103-82313 and 82503-85703, both intervals with behaviour code 3 as the last digit, were enrolled. ${ }^{16}{ }^{17}$ Cases of small bowel carcinoid tumour were also ascertained, but they were not included in the present analysis because the pathology of this tumour is different from that of SBA, and there is no reason to think that these two diseases share the same aetiology. One pathologist (PST), blinded to exposure, reviewed a representative $\mathrm{HE}$ stained histological slide together with the local pathology report.

Of the 168 patients with a locally made histological diagnosis of SBA, 61 (36\%) were not accepted by our pathologist. Thirty four of these were reclassified as biliary tract adenocarcinomas originating from the ductal epithelium of the papilla of Vater, 11 were other subtypes (stromal tumours, adenomas, melanomas), and the primary origin of the remaining 16 tumours could not be established definitely.

The expected number of cases was calculated based on data from EUROCIM, ${ }^{18}$ except for Sweden where cancer registry data were used. The expected, identified, and accepted number of cases after pathology review were, for each country, Denmark (26/49/24), Sweden $(51 / 32 / 27)$ (sarcomas included in expected), France (27/38/31) and Spain (12/26/
12), Germany (8/14/7) (expected number only reported for Hamburg) and Italy (11/9/6). In nearly all countries the expected number of cases for the study regions were too high, because tumours of the periampullary region are often misclassified as duodenal cancers. Case identification was judged as nearly complete in Denmark, Sweden, France, and Spain, whereas in the centres in Germany and Italy too little diagnostic information was available to identify as many as expected. In Denmark we further evaluated the number of identified cases 1 year after the end of the study by comparing our data based on regional pathology and patient registries with cancer registry data, and no further cases were identified.

The study was population based except in Spain where the controls were hospital patients with cancer of the colon. Population controls were randomly selected from the study base at each centre, and they were frequency matched with cases in 5 year age bands by sex and region (Denmark, Sweden, Germany, France, Italy). The goal was to get at least four controls per case for the most frequent of the seven rare cancer types within each stratum. As the control groups for all seven cancer types were pooled for the analyses of each cancer type to obtain the best possible precision, a controlcase ratio much higher than four was obtained in the SBA study. This was particularly true for men as two of the other rare cancers studied (gall bladder and breast cancer) were restricted to men. For the same reasons the control group included a larger proportion of younger subjects reflecting the pooling of controls selected for seven different rare cancers of which some occurred more often among the younger population than was the case for SBA. For practical reasons the controls were selected every 3-6 months during the study period, in Germany from a pool of subjects representing the population at the start of the study. In Spain, hospital controls with a diagnosis of adenocarcinoma of the colon were selected from the same hospitals as the cases, and matched for age and sex. If the index person was dead or too ill to participate, the next of kin was interviewed if possible.

Of the 107 cases of SBA, 580 colon cancer controls (Spain), and 3335 population controls

Table 1 Recruitment of cases with small bowel adenocarcinoma and controls by country

\begin{tabular}{|c|c|c|c|c|c|c|c|}
\hline & $\begin{array}{l}\text { Denmark } \\
n\end{array}$ & $\begin{array}{l}\text { Sweden } \\
n\end{array}$ & $\begin{array}{l}\text { France } \\
n\end{array}$ & $\begin{array}{l}\text { Germany } \\
n\end{array}$ & $\begin{array}{l}\text { Italy } \\
n\end{array}$ & $\begin{array}{l}\text { Spain } \\
n\end{array}$ & $\begin{array}{l}\text { Total } \\
n\end{array}$ \\
\hline \multicolumn{8}{|l|}{ Cases: } \\
\hline Eligible & 24 & 27 & 31 & 7 & 6 & 12 & 107 \\
\hline Dead or too ill to participate & 3 & 1 & 4 & - & - & 2 & 10 \\
\hline No contact established & - & - & 1 & - & - & - & 1 \\
\hline Refused to participate or no response & 8 & 5 & 2 & 1 & - & 1 & 17 \\
\hline All cases interviewed & 13 & 21 & 24 & 6 & 6 & 9 & 79 \\
\hline Index case subjects interviewed & 10 & 16 & 22 & 4 & 5 & 8 & 65 \\
\hline Surrogate case subjects interviewed & 3 & 5 & 2 & 2 & 1 & 1 & 14 \\
\hline \multicolumn{8}{|l|}{ Controls: } \\
\hline Population $(\mathrm{P})$ or cancer $(\mathrm{C})$ controls & $\mathrm{P}$ & $\mathrm{P}$ & $\mathrm{P}$ & $\mathrm{P}$ & $\mathrm{P}$ & $\mathrm{C}$ & - \\
\hline Eligible & 583 & 407 & 630 & 1325 & 390 & 580 & 3915 \\
\hline Dead or too ill to participate & 1 & - & 4 & 46 & 4 & - & 55 \\
\hline No contact established & - & - & 20 & 70 & 27 & - & 117 \\
\hline Refused to participate or no response & 262 & 177 & 121 & 477 & 56 & 1 & 1094 \\
\hline All controls interviewed & 320 & 230 & 485 & 732 & 303 & 579 & 2649 \\
\hline Index control subjects interviewed & 318 & 229 & 477 & 724 & 298 & 523 & 2569 \\
\hline Surrogate control subjects interviewed & 2 & 1 & 8 & 8 & 5 & 56 & 80 \\
\hline
\end{tabular}




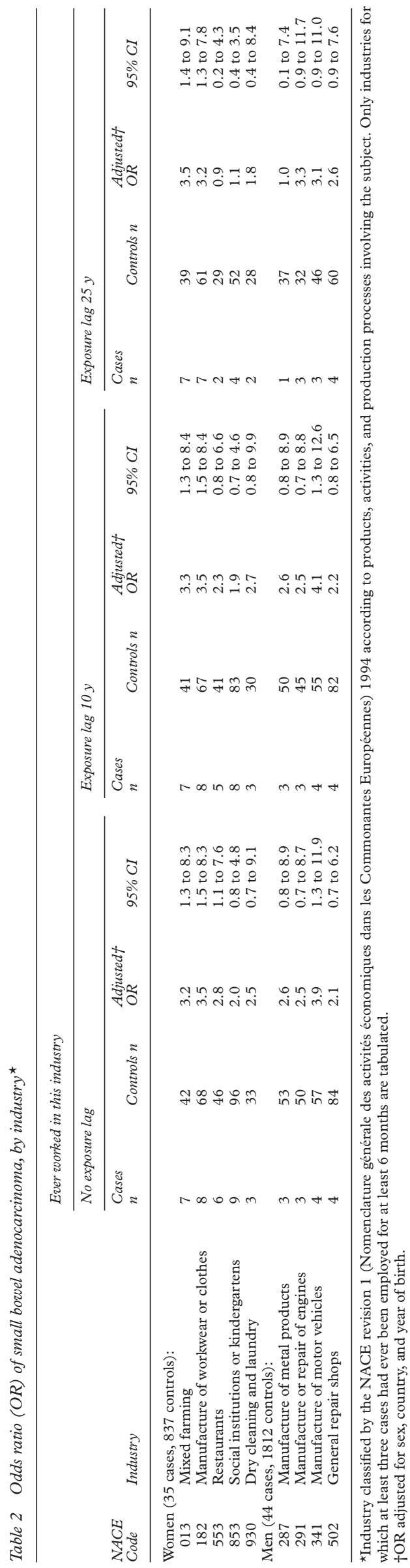

accepted for study, 79 cases (44 male, 35 female) and 2649 controls (1812 male, 837 female; 579 colon cancer controls and 2070 population controls) were interviewed (table $1)$. The interviews were conducted by trained interviewers face to face $(65.9 \%)$, by telephone $(33.6 \%)$, or both $(0.5 \%)$. The mean time from diagnosis to interview for cases was 7.9 months. The response rate for cases was $74 \%$ (range $54 \%$ in Denmark to $100 \%$ in Italy), and for controls $64 \%$ (range $55 \%$ in Denmark to $99.8 \%$ in Spain). The age distribution (35-49 years, 50-59 years, and 60-69 years of age) for cases and controls was $19 \%, 32 \%$, and $49 \%$, and $37 \%, 29 \%$, and $34 \%$, respectively.

\section{EXPOSURE ASSESSMENT}

A standard questionnaire was developed cooperatively between all the centres; it concerned occupational exposure and lifestyle factors. The original version was written in English and translated into the six national languages (Danish, Swedish, German, French, Italian, Spanish). Back translation to English was performed to ensure uniformity. A complete list was collected of all employment periods since leaving primary school of 6 months or more. All major job changes within a company were included as separate jobs - that is, when the products, activities, tasks, job title, materials, or chemicals involving the interviewee had changed significantly. For each job, the starting and ending year were reported, together with working hours/week, materials handled, chemical exposure, and occupations held by nearby workers. Industry and occupation were coded separately for each occupational period and all jobs were given one main code and up to two subcodes according to the national industrial classification of all economic activities (NACE) classification of industry (4 digits) ${ }^{19}$ and the international standard classification of occupations (ISCO) classification of occupation (5 digits), ${ }^{20}$ based on the aggregated available information.

Work specific questionnaires were used for in depth interviews on 27 specific work tasks with possible chemical, physical, or biological exposures assumed to carry a carcinogenic potential, when the subjects had ever been engaged in these occupational activities.

Information was also collected on socioeconomic and demographic status, lifestyle factors, reproductive factors, and medical history, including exposure to radiation and long standing medical treatment.

\section{STRATEGY OF ANALYSIS}

The NACE codes and the ISCO codes were scrutinised at a three digit level. Industries and occupations with at least three exposed cases among women or men separately in each category were selected for further evaluation. This strategy was determinated before data analysis.

Subjects were classified according to whether they had ever been engaged in the specified industries or occupation. Account was taken for a possible latency time by disregarding jobs held during the 10 years or the 25 


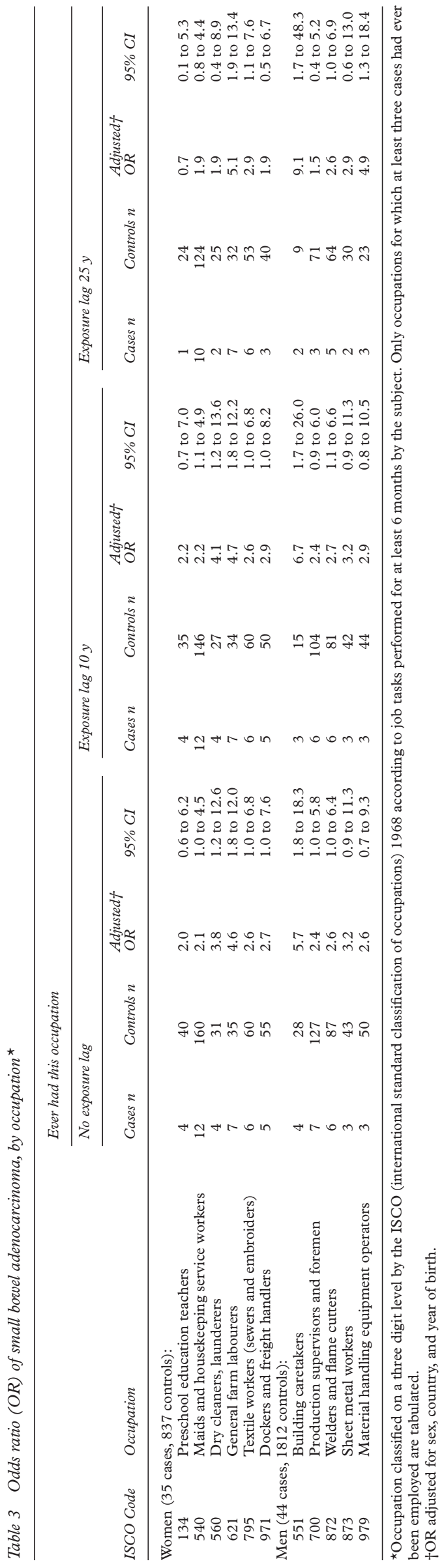

years before interview (10 and 25 year exposure lag, respectively). Data were analysed for men and women separately because the two sexes may perform different tasks even if they share occupation or industry. However, specific exposures were evaluated for both sexes combined. Further details about the study have been described elsewhere. ${ }^{21}$

The study was made in accordance with the requirements of the ethics committees in each of the participating countries or regions.

\section{STATISTICAL METHODS}

Crude and adjusted ORs were obtained by unconditional logistic regression with 95\% confidence intervals (95\% CIs). All adjusted estimates were obtained from a model that included country, year of birth, and sex, as controls were matched on these variables.

Year of birth was used as a continuous variable. $^{22}$ A more detailed adjustment for region did not improve the model. Smoking, alcohol consumption, and a previous diagnosis of Crohn's disease did not influence the ORs obtained from this model by $10 \%$ or more, and were not included in any of the final models. ${ }^{23}$ For analyses of trend we introduced continuous exposure variables into the models.

Due to the small numbers we repeated the analyses with an exact test for stratified analyses (StatXact). This method only allowed for stratification by country (six levels), year of birth (three levels), and sex. These additional analyses did not change the results significantly and thus, we have only presented the results from the unconditional logistic regression models.

\section{Results}

For 20 industries (nine among women, 11 among men) and 24 occupations (11 among women, 13 among men), at least three SBA cases had ever been employed for at least 6 months. Five industries among women and four among men were identified with at least a twofold increased OR for SBA (table 2). Only manufacture of workwear and other clothes and mixed farming among women, and manufacture of motor vehicles among men were significantly increased, when lagged by 10 years. The ORs remained stable when lagged for 25 years.

We conducted an additional analysis based on the NACE codes on a four digit level to separate the dry cleaning and the laundry industries. This separation showed an OR of 6.5 (1.6 to 26.9) for the dry cleaning industry based on three cases and 10 controls, whereas a low risk was found in the laundry industry. For dry cleaning the OR was 7.5 (1.7 to 32.4 ) and 5.0 (0.9 to 27.7) when disregarding jobs held for the last 10 years and 25 years, respectively. A similar separation on a four digit level was not possible for the other industries or occupations identified with increased ORs.

Table 3 shows comparable data for occupation. Among the women six occupations showed ORs above two, of which five were significantly increased when lagged by 10 years: general farmers, dry cleaners and launderers, 


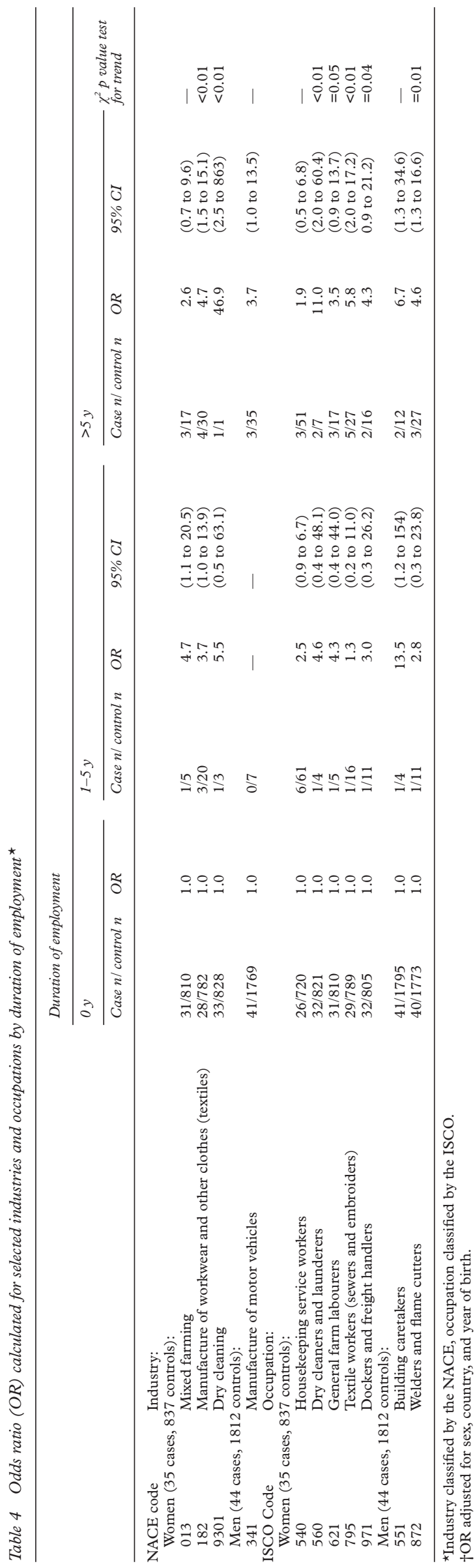

textile workers, dockers, and housekeeping service workers (table 3). Among the men five occupations showed ORs above 2.0, of which building caretakers and welders were significantly increased. These findings were still present when lagged for 25 years.

Table 4 presents the ORs by duration of employment for the industries and occupations with suggested increased occurrence of SBA (OR above two and significantly increased). Among women increasing duration of employment in the dry cleaning industry, and with an occupation as a dry cleaner or launderer were associated with increasing occurrence of SBA. This pattern was also found for women in the workwear and clothing industry, among female textile workers, dockers or freight handlers, general farm labourers, and male welders.

In depth exposure data were available for welding based on supplementary task specific questionnaires (table 5). Among workers who had ever performed welding, we found an association with semiautomatic arc welding (metal inert gas welding (MIG) or gas metal arc welding (MAG); OR 5.0 (1.3 to 19.6) based on six exposed cases and 94 exposed controls). Use of a cellulosic electrode in arc welding was also associated with increased risk. We did not find any association between SBA and the use of pesticides or herbicides in any job.

Rerunning all the analyses with the exclusion of the colon cancer controls together with the Spanish cases did not change these estimates by $10 \%$ or more (data not shown).

\section{Discussion}

This study suggests that female dry cleaners, textile workers, dockers or freight handlers, general farm labourers, and male welders have an increased occurrence of small bowel adenocarcinoma. Among welders, exposures related to semiautomatic arc welding were suggested as a possible risk factor.

The quality of exposure information is crucial when studying occupational causes of cancer. We recorded lifetime job histories including main task, subtasks, and materials and chemicals handled, which were classified according to standard industrial and occupational classification schemes, whereas earlier studies on SBA and occupation have been based on register information about job title at one time or on case reports. Information about occupation and industry is to be regarded as a proxy of occupational exposures. In well defined occupational groups with only few exposures in common, occupation can reflect specific exposures. ${ }^{13}$ The validity of occupational histories, compared with register information and specific exposure information is in general judged to be valid. ${ }^{24-26}$ We also identified relevant time windows of exposure, disregarding jobs held for the past 10 years and 25 years, respectively, and so taking into account the expected latency time for solid malignancies.

Another strength of this study is the high number of histologically verified incident cases of SBA. Because cases were enrolled from 
Table 5 Odds ratio for small bowel adenocarcinoma according to selected occupational exposures related to welding and pesticide use

\begin{tabular}{|c|c|c|c|c|c|}
\hline Exposure & Cases $n$ & Controls $n$ & Crude OR & Adjusted OR & $95 \% C I$ \\
\hline \multicolumn{6}{|l|}{ Welding (12 cases, 384 controls): } \\
\hline Welding in mild steel & 9 & 243 & 1.7 & 1.6 & 0.3 to 7.3 \\
\hline Welding in stainless steel & 5 & 172 & 0.9 & 0.9 & 0.3 to 3.0 \\
\hline Clean up the metal with trichloroethylene ${ }^{\star}$ & 3 & 92 & 1.1 & 0.6 & 0.2 to 2.6 \\
\hline Gas welding with oxyacetylene torch $\star$ & 7 & 222 & 1 & 1.5 & 0.4 to 5.5 \\
\hline Flame cutting ${ }^{\star}$ & 7 & 212 & 1.1 & 1.0 & 0.3 to 3.6 \\
\hline Electric resistance welding ${ }^{\star}$ & 4 & 135 & 0.9 & 1.0 & 0.3 to 3.5 \\
\hline Manual metal arc welding $(\mathrm{MMA})^{\star}$ & 8 & 226 & 1.4 & 1.9 & 0.4 to 8.3 \\
\hline Arc welding with tungsten electrode $(\mathrm{TIG})^{\star}$ & 4 & 50 & 3.3 & 2.7 & 0.6 to 11.7 \\
\hline Semi-automatic arc welding $(\mathrm{MIG} / \mathrm{MAG})^{\star}$ & 6 & 94 & 3.1 & 5.0 & 1.3 to 19.6 \\
\hline Plasma arc welding $\star$ & 2 & 25 & 3.1 & 3.0 & 0.5 to 17.9 \\
\hline Type of electrode in arc welding: & - & - & - & - & - \\
\hline Rutile & 3 & 63 & 1.7 & 2.6 & 0.6 to 11.6 \\
\hline Basic & 2 & 85 & 0.7 & 0.7 & 0.1 to 3.3 \\
\hline Cellulosic & 2 & 21 & 3.5 & $22.6 \dagger$ & 2.4 to 213 \\
\hline Place where the welding was performed: & - & - & - & - & - \\
\hline In close probing quarters & 2 & 168 & 0.3 & 0.3 & 0.1 to 1.7 \\
\hline In open air (outdoors) & 5 & 139 & 1.3 & 1.2 & 0.4 to 4.3 \\
\hline In small room (workshop) & 4 & 184 & 0.5 & 0.5 & 0.1 to 1.8 \\
\hline In factory hall & 9 & 182 & 3.3 & 3.7 & 0.9 to 15.3 \\
\hline Use of asbestos made protective equipment & 5 & 109 & 1.8 & 2.3 & 0.6 to 8.5 \\
\hline Performance of $x$ ray tests & 1 & 9 & 3.8 & 4.0 & 0.4 to 42.6 \\
\hline \multicolumn{6}{|l|}{ Use of pesticides ( 79 cases, 2649 controls): } \\
\hline Pesticides, all kinds of* & 8 & 240 & 1.1 & 1.0 & 0.5 to 2.2 \\
\hline Herbicides ${ }^{\star}$ & 6 & 141 & 1.2 & 0.9 & 0.1 to 6.3 \\
\hline
\end{tabular}

^Estimate did not change significantly after adjustment for duration of exposure.

†Adjustment for country increases the estimate from 3.5 to 22.6 (few cases were exposed).

different countries and regions, one might expect a high degree of diagnostic heterogeneity. By having one expert pathologist to review the histological slides and pathology reports from all the cases without knowledge of exposure, we could overcome this, and all cases were diagnosed according to identical criteria.

Several methodological issues should be considered when interpreting these data. In studies based on self reported data, findings may always be flawed by recall bias. ${ }^{27}$ Hospital controls may overcome this (as well as increasing the participation rate), but they must be selected among patients with diseases not associated with occupation. We therefore selected patients with colon cancer as controls because there is no strong indication of occupational risk factors for this disease. Some similarities in risk factors for SBA and colon cancer outside the work environment have, however, been suggested - for example, dietary factors (high intake of bread, alcohol, and salt cured or smoked food items) - but the evidence is weak and inconsistent. ${ }^{48}$ If we restricted the control group to population controls (excluding Spain), the risk estimates were comparable with the results presented; we therefore decided to keep the complete study population.

Because SBA is often rapidly fatal, we interviewed next of kin when the index person was dead or too ill to participate. If exposures are related to prognosis, this has probably reduced the potential for selection bias as well as increasing the statistical power, but the number of proxy responders was small.

As competing causes of SBA are expected to be rare, the risk for confounding was expected to be small, but it cannot be ruled out as the cause of this disease is unknown.

The main problem in interpreting our findings is the many associations examined. Some were likely to be spurious by chance alone. However, we found indications of increased risk in more occupations and indus- tries than would be expected from the 20 industries and 24 occupations examined.

We found an increased occurrence of SBA among textile workers. Similar findings were presented in a follow up of the 1970 census in Denmark. ${ }^{6}$ Exposures characterising this occupation are textile and dye dust, and waterproof and fireproof agents. ${ }^{29}$ Our finding of an association between dry cleaning and SBA has not been reported earlier. Possible carcinogenic exposures of dry cleaning are perchlorethylene, fluorocarbons, and benzene. Exposure to perchlorethylene or working within the dry cleaning industry has been associated with leukaemia, oesophageal cancer, and bladder cancer. $^{30}$ Welders and people working with manufacture of motor vehicles showed an increased risk of SBA and may be exposed to various substances, including welding fumes, asbestos, trichloroethylene, or other organic solvents. Numerous earlier studies of welders have not shown an increased occurrence of SBA-but this may well be due to chance because of the rarity of this disease.

An increased occurrence of SBA among farmers, an occupational group with a low overall risk of cancer, may be due to exposure to pesticides, ${ }^{810}$ but we found no association with this exposure. The increased occurrence among dockers, freight handlers, and building caretakers has not been described before, and there is no obvious carcinogenic exposure in these occupations.

In conclusion, the increased occurrence of SBA in dry cleaners, textile workers, general farm labourers, dockers or freight handlers, and welders may suggest that exposures in these occupations are related to SBA. However, this study was purely explorative, and all findings should be regarded as tentative and needing further investigation. Overall, the excess occurrences found were small. If an increased risk of SBA is associated with these occupations and industries, the causal factors 
would be expected to affect only a limited subset of the workers involved. Thus, further studies of occupation and small bowel adenocarcinoma should focus on specific exposures in the identified occupations.

We gratefully acknowledge collaboration from patients, controls, participating hospitals, and data providers. Occupational risk factors for rare cancers of unknown aetiology was supported BIOMED, grant No BMH1 CT 93-1630, and national funding agencies. Denmark: The Strategic Environment Programme, agencies. Denmark: The Strategic Environment Programme,
grant No 92.01.015.7-06, and the Danish Epidemiology grant No 92.01.015.7-06, and the Danish Epidemiology
Science Centre (the activities of the centre are financed by a Science Centre (the activities of the centre are financed by a grant from the Danish National Research Foundation). France: Ligue Nationale Contre le Cancer, Fédération Nationale des Centres de Lutte contre le Cancer, Fondation de France, contract 955368, Institut National de la Santé et de la Recherche Médicale (INSERM) contract Réseau en Santé Publique 4R006A, French Ministry of Environment, contract 237.01. 94.40182. Germany: Federal Ministry for Education, Science, Research, and Technology (BMBF), grant 01-HP-684/8. Italy: The Italian Association for Cancer Research (AIRC), The Italian Ministry of Labour. Spain: Fondo de Investigación de la Sanitarie, Ministerio de Sanidad y Consumo, Unidad de Investigación Clinico-Epidemiológica, Hospital Dr Peset, Generalitat Valenciana (FISS 95/0044-01, 96/0043-01); Departmento de Sanidad y Consumo, Gobierno Vasco; Fondo de Investigacion de la Sanitaria Ministerio de Sanidad y Consucion de la Sanitaria, Ministerio de Sanidad y Consumo, Ayuda a la Investigación del Departamento de Salud del Gobierno de Navarra. Sweden: Swedish Council for Work Life Research, Research Foundation of the Department of Oncology in Umeå, Swedish Society of Medicine, Lund University Hospital
Research Foundation, Gunnar, Arvid and Elisabeth Nilsson Research Foundation, Gunnar, Arvid and Elisabeth Nilsson Cancer Foundation, Örebro County Council Research Com-
mittee, Örebro Medical Center Research Foundation, John and mittee, Orebro Medical Center Research Foundation, John and Berta Kamprad Foundation for Cancer Research.

\section{Appendix: The European Study Group on} Occupational Causes of Rare Cancers

Denmark (Herman Autrup, Henrik Kolstad, Linda Kaerlev, Elsebeth Lynge, Jorn Olsen, Lisbeth Norum Pedersen, Svend Sabroe, pathologists: Preben Johansen, Stein Poulsen, Peter Stubbe Teglbjaerg, Mogens Vyberg,). France (Pascal Guénel, Joëlle Févotte and the members of the FRANCIM association: Patrick Arveux, Antoine Buemi, Paule-Marie Carli, Gilles Chaplain, Jean-Pierre Daurès, Jean Faivre, Pascale Grosclaude, Anne-Valérie Guizard, Michel Henry-Amar, Guy Launoy, Francois Ménégoz, Nicole Raverdy, Paul Schaffer). Germany (Wolfgang Ahrens, Cornelia Baumgardt-Elms, Sibylle Gotthardt, Ingeborg Jahn, Karl-Heinz Jöckel, Hiltrud Merzenich, Andreas Stang, Christa Stegmaier, Antje Timmer, Hartwig Ziegler). Italy (Terri Ballard, Franco Bertoni, Giuseppe Gorini, Sandra Gostinicchi, Giovanna Masala, Enzo Merler, Franco Merletti, Lorenzo Simonato, Paola Zambon). Latvia (Irena Rogovska, Galina Sharkova, Aivars Stengrevics). Lithuania (Jolita Gibaviciene, Laimonas Jazukevicius, Juozas Kurtinaitis, Poma Pociute). Portugal (Noemia Alfonso, Altamiro Costa-Pereira, Sonia Doria, Carlos Lopes, José Manuel Lopes, Ana Miranda, Cristina Santos). Spain (M Adela Sanz Aguado, Juan J Aurrekoetxea, Concepción Brun, Alicia Córdoba, Miguel Angel Martínez González, Francisco Guillén Grima, Rosa Guarch, Agustin Llopis González, Blanca Marín, Amparo Marquina, María M Morales SuárezVarela, Inés Aguinaga Ontoso, JM Martínez Peñuela, Ana Puras, Francisco Vega, Maria Aurora Villanueva Guardia). Sweden (Mikael Eriksson, Lennart Hardell, Irene Larsson, Hakan Olson, Monica Sandström, Gun Wingren). Switzerland (Jean-Michel Lutz). United Kingdom (Janine Bell, Ian Cree, Tony Fletcher, Alex JE Foss).
1 Parkin DM, Whelan SL, Ferlay J, et al. International Agency for Research on Cancer. Cancer incidence in five continents. Vol VII. Lyon: IARC Sci Publ 1997;143:1-1240.

2 Munkholm P, Langholz E, Davidsen M, et al. Intestinal cancer risk and mortality in patients with Crohn's disease. Gastroenterology 1993;105:1716-23.

3 Watson P, Lynch HT. Extracolonic cancer in hereditary non-polyposis colorectal cancer. Cancer 1993;71:677-85.

4 Negri E, Bosetti C, La Vecchia C, et al. Risk factors for adenocarcinoma of the small intestine. Int $f$ Cancer 1999;82:171-4.

5 Kato I, Tominaga S, Terao C. An epidemiological study on marital status and cancer incidence. Fpn f Cancer Res 1989; 80:306-11.

6 Kolstad H, Lynge E, Olsen J, et al. Occupational causes of some rare cancers. A literature review. Scand 7 Soc Med Suppl 1992;48:1-148.

7 Lynge E, Thygesen L. Occupational cancer in Denmark. Cancer incidence in the 1970 census population. Scand $\mathcal{F}$ Work Environ Health 1990;16(suppl 2):3-35.

8 Reif J, Pearce N, Kawachi I, et al. Soft-tissue sarcoma, nonHodgkin's lymphoma and other cancers in New Zealand forestry workers. Int 7 Cancer 1989;43:49-54.

9 Siemiatycki J. Interpretation of findings. In: Siemiatycki J, eds. Risk factors for cancer in the workplace. Boston: CRC Press, 1991;7:1-8.

10 Newell KW, Ross AD, Renner RM. Phenoxy and picolinic acid herbicides and small-intestinal adenocarcinoma in sheep. Lancet 1984;ii:1301-5.

11 Graham S, Blanchet M, Rohrer T. Cancer in asbestosmining and other areas of Quebec. F Natl Cancer Inst 1977; 59:1139-45.

12 Lashner BA. Risk factors for small bowel cancer in Crohn's disease. Dig Dis Sci 1992;37:1179-84.

13 Mancuso TF. Mesothelioma among machinists in railroad and other industries. Am f Ind Med 1983;4:501-13.

14 Vianna NJ, Brady J, Harper P. Angiosarcoma of the liver: a signal lesion of vinyl chloride exposure. Environ Health Perspect 1981;41:207-10.

15 Martland HS. Occupational poisoning in manufacture of luminous watch dials. $\mathcal{F} A M A$ 1929;92:466-73.

16 World Health Organisation. International classification of diseases for oncology (ICD-O). Geneva: WHO, 1976.

17 World Health Organization. International classification of diseases for oncology (ICD-O). Geneva: WHO, 1990.

18 International Agency for Research on Cancer. European network of cancer registries "EUROCIM", users manual, 2nd ed. Lyon: IARC, 1995.

19 EC Commission. National industrial classification of all economic activities (NACE), rev1, 2nd ed. Luxembourg Office for Official Publications of the EC, 1993.

20 International Labour Office. International standard classification of occupations (ISCO). Geneva: ILO, 1968.

21 Kaerlev L, Teglbjaerg PS, Sabroe S, et al. Is there an association between alcohol intake or smoking and small bowel adenocarcinoma? Results from a European multi-center case-control study. Cancer Causes Control 2000 (in press).

22 Brenner $\mathrm{H}$, Blettner $\mathrm{M}$. Controlling for continuous confounders in epidemiologic research. Epidemiology 1997; 8:429-4.

23 Maldonado G, Greenland S. Simulation study of confounder-selection strategies. Am $\mathcal{F}$ Epidemiol 1993;138: 923-36.

24 Brisson C, Vezina M, Bernard PM, et al. Validity of occupational histories obtained by interview with female workers. Am f Ind Med 1991;19:523-30.

25 Ahlborg GA, Jr. Validity of exposure data obtained by questionnaire. Two examples from occupational reproductive studies. Scand 7 Work Environ Health 1990;16:284-8.

26 Joffe M. Validity of exposure data derived from a structured questionnaire. Am $\mathcal{F}$ Epidemiol 1992;135:564-70.

27 Drews CD, Greenland S. The impact of differential recall on the results of case-control studies. Int F Epidemiol 1990; 19:1107-12.

28 Wu AH, Yu MC, Mack TM. Smoking, alcohol use, dietary factors and risk of small intestinal adenocarcinoma. Int 7 Cancer 1997;70:512-7.

29 International Agency for Research on Cancer. Some flame retardants and textile chemicals, and exposures in the textile manufacturing industry. IARC Monogr Eval Carcinog Risks Hum 1990;48:1-278.

30 Weiss NS. Cancer in relation to occupational exposure to perchloroethylene. Cancer Causes Control 1995;6:257-66. 